\title{
A Comparative Trial of the Efficacy of Mefenamic Acid and Tranexamic Acid for Treatment of Menorrhagia Induced by Copper T-380A IUD
}

\author{
Nasrin Saharkhiz ${ }^{1}$, Farnaz Ehdaeevand ${ }^{2}$, Anahita Tavana ${ }^{3 *}$, Zahra Majdfar $^{2}$, Masoumeh Fallahian ${ }^{1}$
}

\begin{abstract}
Objectives: To evaluate and compare the efficacy of mefenamic acid and tranexamic acid in controlling menorrhagia induced by Copper T-380A intrauterine device (IUD).

Materials and Methods: Women aged 18-40 years with heavy menstrual bleeding, who were using TCu380A IUD, were randomised to receive tranexamic acid (group 1, $\mathrm{n}=120$ ) or mefenamic acid (group 2, $\mathrm{n}=90$ ), $500 \mathrm{mg}$ three times daily for 3-5 days of three consecutive menstrual cycles. Changes in menstrual blood loss volume and duration were assessed using the questionnaire form filled out before the treatment and every month for 3 months. Method of calculation of blood loss volume was instructed to all participants at the first visit. Haemoglobin $(\mathrm{Hb})$ concentration level of participants were also assessed before and after the treatment. Data were analysed using $t$ test, paired sample t test, non-parametric Mann-Whitney test, chi-squared test, and analysis of covariance (ANCOVA).

Results: After the treatment, mean blood volume decreased significantly, by $42.3 \%$ in group 1 and by $44.5 \%$ in group 2, but their difference was not significant. Mean menstrual days decreased significantly, by $64 \%$ in group 1 and by $62 \%$ in group 2 ; however, their difference was not significant. $\mathrm{Hb}$ concentration level before and after the treatment was not significantly different between the 2 groups. The peak effect of both drugs was observed at the end of the second month of treatment.

Conclusion: Tranexamic acid and mefenamic acid have the same significant effect in reducing mean blood loss volume and duration of menstruation in TCu380A IUD users.

Keywords: Intrauterine devices, Copper, Mefenamic acid, Menorrhagia, Tranexamic acid
\end{abstract}

\section{Introduction}

Intrauterine device (IUD) is one of the most reliable methods of contraception. Worldwide, over $15 \%$ of married women use intrauterine contraception (1). Copper-containing IUDs (Cu-IUDs), introduced in the late 1960s, are available in a variety of types and are mostly categorized based on their shape and their levels of copper. The Copper T380-A is considered the most effective CuIUD (2). Currently, TCu380A IUD is the sole Cu-IUD available in public health clinics in Iran.

Abnormal uterine bleeding is one of the most frequent causes for $\mathrm{Cu}-\mathrm{IUD}$ discontinuation. Menorrhagia is defined as the amount of bleeding more than or equal to 80 $\mathrm{mL}$ per menstrual cycle, or menses that lasts longer than 7 days (3). Excessive bleeding accounts for $60 \%$ of primary care consultations for menstrual problems and $12 \%$ of all gynaecology referrals. This can not only interfere with social activities and day-to-day work of those affected by this condition, but also have a major impact on their quality of life (4). Because of the low failure rate and high efficacy of $\mathrm{Cu}$-IUDs, increasing the satisfaction of users and lowering the discontinuation rate of this method is of utmost importance. Therefore, it is essential to evaluate the effect of inexpensive and widely available medications that could decrease the amount of menstrual blood loss in TCu380A IUD users.

Nonsteroidal anti-inflammatory drugs (NSAIDs), such as mefenamic acid, act as inhibitors of prostaglandin synthetase and decrease the release of endometrial prostaglandin. Therefore, they potentially result in a reduction in menstrual bleeding, even in the presence of $\mathrm{Cu}$-IUDs (5). Other medications, such as anti-fibrinolytic agents (e.g. tranexamic acid), are recommended by the World Health Organization (WHO) as the treatment for heavy or prolonged menstrual bleeding among $\mathrm{Cu}-\mathrm{IUD}$ users (6).

In a systematic review on treatment of bleeding irregularities in women using Copper-containing IUDs by Godfrey et al, NSAIDs were the most widely studied medications for reduction of blood loss in the presence of a Cu-IUD. Other less widely studied, but possibly effective, medications in reducing bleeding in $\mathrm{Cu}$ -

Received 8 March 2017, Accepted 25 June 2017, Available online 27 July 2017

${ }^{1}$ Infertility and Reproductive Health Research Centre, Shahid Beheshti University of Medical Sciences, Tehran, Iran. ${ }^{2}$ Family Health Department of Deputy forHealth Affairs, Shahid Beheshti University of Medical Sciences, Tehran, Iran. ${ }^{3}$ College of Natural Sciences, University of Texas at Austin, Austin, Texas, USA.

*Corresponding Authors: Farnaz Ehdaeevand, Tel: +98 912145 2835, Email: Drehdayivand@yahoo.com; Anahita Tavana, Tel: +1 7133670763 , Email: anahita.tavana@utexas.edu 
IUD users were anti-fibrinolytic agents, which help prevent the disintegration of blood clots (2). Although intrauterine and intramuscular administrations result in lower gastrointestinal side effects, tranexamic acid was administered orally in most studies, due to its ease of use (7). Tranexamic acid was first approved in the 1980s as an injection with the brand name of Cyklokapron (Pfizer) to prevent or reduce bleeding during and following tooth extraction in haemophilia patients. In clinical trials, menstrual blood loss was significantly reduced in women who received Lysteda (tranexamic acid tablet) in comparison with those receiving a placebo (8). In this study, we intend to compare the 2 most proposed medications for blood loss reduction in menorrhagic TCu380A IUD users in Shahid Beheshti University of Medical Sciences at primary health care clinics.

\section{Materials and Methods}

This study was a comparative, parallel clinical trial, with single-blind sample collection conducted at 6 health centres of Shahid Beheshti University of Medical Sciences in Tehran from June 2012 to December 2014.

\section{Study Population}

The study population consisted of women aged 18-40 years, who were eligible for IUD insertion according to the state protocol. After IUD insertion, only women who had more than 7 days of menstrual bleeding or menstrual blood volume of greater than $80 \mathrm{~mL}$ were included in the study. The type of IUD used was TCu380A. Women were excluded from the study if they had a history of anatomical abnormalities such as uterine myoma; adenomyosis; coagulopathy, such as thromboembolism or stroke; anticoagulant therapy; drug sensitivity; gastrointestinal bleeding; genital infection; endometritis; and other confounding factors that can lead to increased bleeding. All subjects had a history of regular spontaneous menstrual cycles (cycle length: 24-35 days).

\section{Method}

The method of blood loss volume calculation was instructed to all participants during the first visit. Pictures of bloody sanitary pads smeary to $10,20,30$, and $40 \mathrm{~mL}$ blood were shown to them. Patients were asked to keep a daily record of the number of sanitary pads used and group them according to the pictures of pads that were lightly $(10 \mathrm{~mL})$, mildly $(20 \mathrm{~mL})$, moderately $(30 \mathrm{~mL})$, or completely $(40 \mathrm{~mL})$ saturated (3). If the total score was more than $80 \mathrm{~mL}$ points per menstrual cycle, it was an indication of a greater than $80 \mathrm{~mL}$ blood loss. Participants were placed in either the tranexamic acid (120 subjects) or the mefenamic acid group (90 subjects). Of the 6 health centres, 3 were randomly allocated to provide the patients with tranexamic acid and the other 3 were assigned to provide them with mefenamic acid. The number of women who referred to the first 3 health centres (tranexamic acid group) and were eligible to participate in the study was incidentally higher compared to the other 3 health centres (mefenamic acid group). The first group took two 250 mg capsules of tranexamic acid 3 times a day, and the second group took two $250 \mathrm{mg}$ capsules of mefenamic acid (Ruz Darou, batch no. L-15) 3 times a day. Each group continued taking the capsules for 3-5 days based on the duration of bleeding. Investigators were blinded of the intervention. The intervention for using the drugs during haemorrhage took 3 months. The questionnaire forms were filled out before the treatment as well as every month for 3 months. Our primary outcome measures were days of menstruation, volume of blood loss, and the sequence of bleeding. Secondary outcome measure was haemoglobin $(\mathrm{Hb})$ concentration on admission and the end of the treatment.

\section{Statistical Analysis}

Paired sample $t$ test was used to compare the numerical variables of the 2 groups and $t$ test was used for the 2 independent samples. For ordinal data, non-parametric Mann-Whitney test was employed and chi-squared test was performed to compare the categorical data. Moreover, for analysing the trend of bleeding reduction over time, the repeated measures analysis of covariance (ANCOVA) was used, with adjustment for baseline bleeding. $P$ value of $<0.05$ was considered significant. All analysis was performed using the SPSS software (version 16).

\section{Results}

The total number of women enrolled in this study was 210 , with 120 women in group 1 (tranexamic acid) and 90 women in group 2 (mefenamic acid). There were no significant differences between the mean age, number of pregnancies and deliveries, educational status (Table 1 ), and previous contraception methods (Table 2) of the 2 groups according to $t$ test and chi-squared analysis. Baseline mean blood loss in the 2 groups was significantly different, which is incidental in different centres. Baseline $\mathrm{Hb}$ was not significantly different between the 2 groups (Table 1). Mean menstrual days in both group 1 and group 2 decreased significantly (from 10.22 to 3.58 days in group 1 and from 12.33 to 4.63 days in group 2 ); this reduction was progressive during the 3 months of the treatment. The $P$ value was $<0.05$ in both groups according to independent samples $t$ test (Table 3). These decreases were $64 \%$ in group 1 and $62 \%$ in group 2 and the difference between the groups was not significant based on chi-squared analysis (Table 4 ). In group 1, the volume of bleeding decreased by $23.43 \%$ after the first month $(P<0.001)$ and by $14.28 \%$ after the second month of the treatment $(P=0.001)$; mean blood loss decreased significantly (by $42.3 \%$ ) compared to mean baseline bleeding after 3 months, from $256.57 \mathrm{ml}$ to $160.61 \mathrm{~mL}$ $(P<0.001)$ (Table 5, Figure 1). In group 2, the volume of bleeding decreased by $24.14 \%$ after the first month $(P<0.001)$, but not progressively after the second month of the treatment; mean blood loss decreased significantly compared to mean baseline bleeding after 3 months, from $170.31 \mathrm{~mL}$ to $96.351 \mathrm{~mL}(P<0.001)$ (Table 5, Figure 1). 
Table 1. Baseline Characteristics of Participants in the Study

\begin{tabular}{|c|c|c|c|}
\hline Characteristic & Mefenamic Acid & Tranexamic Acid & $P$ Value \\
\hline Age, mean (SD) & $31.64(6.41)$ & $31.48(5.49)$ & 0.85 \\
\hline No. of pregnancies, mean (SD) & $2.09(1.25)$ & $2.12(1.15)$ & 0.86 \\
\hline No. of deliveries, mean (SD) & $1.90(1.05)$ & $1.90(0.88)$ & 0.99 \\
\hline Education (beyond high school), \% & 48.9 & 37.5 & 0.12 \\
\hline Job (housewife), \% & 85.6 & 93.3 & 0.06 \\
\hline Baseline $\mathrm{Hb}$ level, mean (SD) & $12.76(0.94)$ & $12.56(2.85)$ & 0.56 \\
\hline
\end{tabular}

Table 2. Previous Contraceptive Method ${ }^{a}$

\begin{tabular}{lcc}
\hline Contraceptive method & Mefenamic acid & Tranexamic acid \\
\hline Oral contraceptive pills, \% & 12.6 & 16 \\
IUD, \% & 17.2 & 14.3 \\
Condom, \% & 26.4 & 24.4 \\
Depo-Provera (DMPA) injection & 4.6 & 1.7 \\
(monthly), \% & 12.6 & 7.6 \\
DMPA injection (3 month), \% & 26.4 & 29.4 \\
Withdrawal, \% & 0 & 5.9 \\
Others, \% & & \\
a $P=0.36$ &
\end{tabular}

Table 3. Comparison of mean (SD) Menstrual Days

\begin{tabular}{lccc}
\hline Menstrual Days & $\begin{array}{c}\text { Mefenamic } \\
\text { Acid }\end{array}$ & $\begin{array}{c}\text { Tranexamic } \\
\text { Acid }\end{array}$ & P Value \\
\hline Before IUD use & $6.70(3.28)$ & $5.94(1.73)$ & 0.04 \\
Baseline after IUD use & $12.33(7.39)$ & $10.22(4.74)$ & 0.02 \\
After the first month & $9.25(5.82)$ & $8.41(4.60)$ & 0.28 \\
After the second month & $8.16(3.70)$ & $7.21(2.91)$ & 0.11 \\
After the third month & $4.63(5.70)$ & $3.58(3.62)$ & 0.16 \\
\hline
\end{tabular}

The reduction in mean blood loss at the end of the threemonth treatment was not significantly different between the 2 groups according to repeated measures ANCOVA (adjusted for baseline); rate of decrease was $42.3 \%$ in group 1 and $44.5 \%$ in group $2(P=0.15)$ (Table 4$)$. The $\mathrm{Hb}$ concentration after the three-month treatment was not significantly different between the 2 groups $(P=0.12)$.

Sixty-three women in group $1(52.5 \%)$ and 53 women in group $2(58.8 \%)$ withdrew from the group before completion of the study. In group 1, reasons behind withdrawals included improvement in condition (26 subjects); removal of the IUD (14 subjects); withdrawal of consent (11 subjects); inability to adhere to the visit schedule (11 subjects); and ineffectiveness of the medication (1 subject). In group 2, reasons for discontinuation were: improvement in condition (18 subjects); removal of the IUD (18 subjects); withdrawal of consent ( 5 subjects); inability to adhere to the visit schedule (5 subjects); ineffectiveness of the medication (3 subjects); incorrect intake of the study medication (2 subjects); side effects (1 subject); and personal reasons (1 subject). Removal of the IUD during the study was higher in group 2; $20 \%$ of women in group 2 removed their IUD compared to only $11.67 \%$ in group 1 (Figure 2). Their difference, however, was not significant based on chisquared analysis $(P=0.36)$.

\section{Discussion}

Findings and Interpretation

At the beginning of the study, 210 women, who met the inclusion criteria, were enrolled in the study with 120 subjects in group 1 and 90 subjects in group 2 . However, during the study, which occurred over a span of 3 months, some women withdrew, with the causes being: improvement in condition, removal of the IUD, side effects, inability to adhere to the visit schedule, withdrawal of consent, incorrect intake of the study medication, personal reasons, and ineffectiveness of the medication. Fourteen subjects in the tranexamic acid group and 17 subjects in the mefenamic acid group (total = 31) withdrew from the study at the end of the first month. Moreover, 35 subjects from the tranexamic acid group (total $=63$ ) and 18 subjects from the mefenamic acid group (total $=53$ ) withdrew from the study at the end of the second month. After the 3-month treatment, 57 subjects in the tranexamic acid group and 37 subjects in the mefenamic acid group had completed the study and statistical analysis was done on all 94 cases (Figure 2). The number of women who withdrew from the study in the mefenamic acid group was more than the tranexamic acid group. This may be partly due to the difference in the rate of satisfaction and efficacy of the drugs. Mean days of bleeding decreased significantly in both groups, by $64 \%$ in the tranexamic acid group and by $62 \%$ in the mefenamic acid group.

In the tranexamic acid group, the volume of bleeding decreased progressively after the first and second months (by 23.45 and $14.3 \%$, respectively). However, the decrease in the third month, in relation to the second month, was not significant. Reduction of bleeding in relation to baseline bleeding after the second and the third months (by 39.5 and $42.3 \%$, respectively) was significant $(P<0.001)$.

In the mefenamic acid group, the volume of bleeding decreased significantly after the first month (by 24.4\%), but not significantly in subsequent months. The reduction in bleeding in relation to baseline after the second and the third months (by 36.6 and $44.5 \%$, respectively) was significant $(P<0.001)$. These results indicate that the peak effect of both drugs was at the end of the second month. 
Table 4. Final Results After 3 Months of Treatment Compared to Baseline

\begin{tabular}{lcc}
\hline & Mefenamic Acid & Tranexamic Acid \\
\hline Blood loss volume, baseline mean (SD) & $170.31(113.31)$ & $256.57(193.58)$ \\
Blood loss volume after the 3-month treatment, mean (SD) & $96.35(62.85)$ & $160.61(139.04)$ \\
Rate of decrease, \% & 44.5 & 42.3 \\
$P$ value & $<0.001$ & $<0.001$ \\
Days of bleeding, baseline mean (SD) & $12.33(7.39)$ & $10.22(4.74)$ \\
Days of bleeding after the 3-month treatment, mean (SD) & $4.63(5.70)$ & $3.58(3.62)$ \\
Rate of decrease, $\%$ & 62 & 6.15 \\
$P$ value & $<0.001$ & 0.16 \\
\hline
\end{tabular}

Table 5. Comparison of mean (SD) Blood Loss Volume Before and After the Treatment

\begin{tabular}{lcc}
\hline & Mefenamic Acid $(\mathrm{n}=\mathbf{3 7})$ & Tranexamic Acid $(\mathrm{n}=\mathbf{5 7})$ \\
\hline Baseline bleeding $(\mathrm{n}=210)$ & $170.31(113.31)$ & $256.57(193.58)$ \\
After the first month $(\mathrm{n}=179)$ & $129.19(80.69)$ & $196.49(151.87)$ \\
After the second month $(\mathrm{n}=126)$ & $110.14(57.11)$ & $168.42(145.13)$ \\
After the third month $(\mathrm{n}=94)$ & $96.35(62.85)$ & $160.61(139.04)$ \\
\hline
\end{tabular}

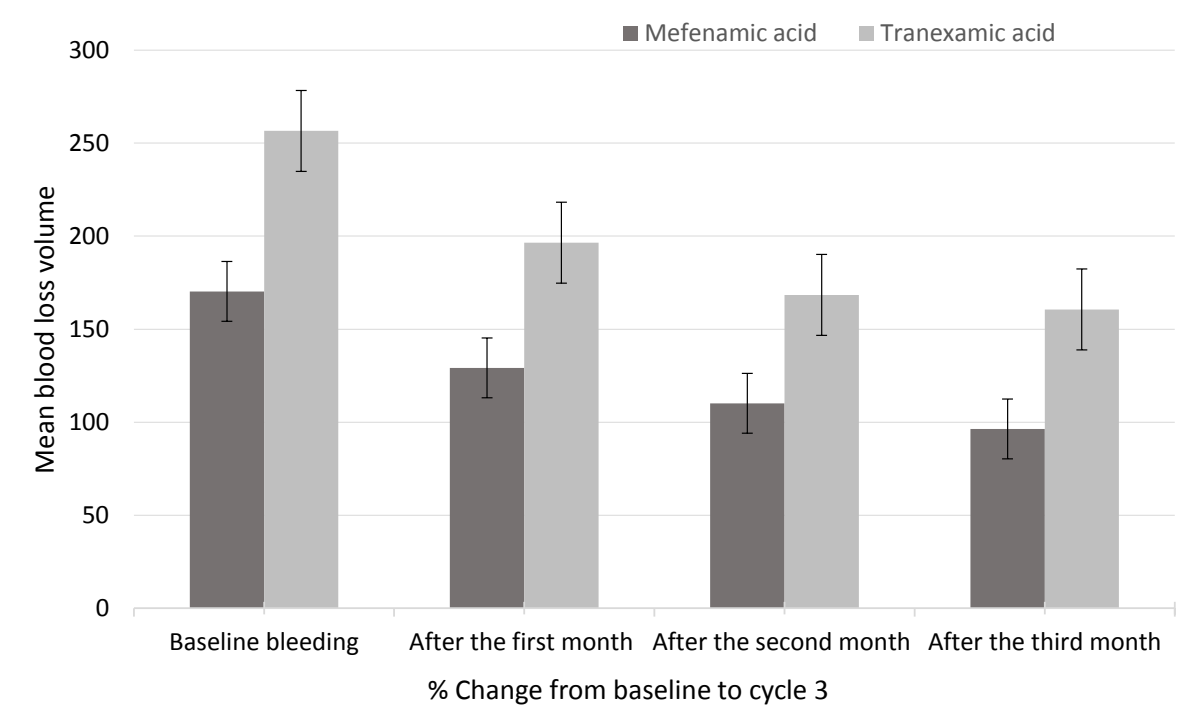

Figure 1. Mean Blood Loss Volume in Mefenamic Acid and Tranexamic Acid Groups After the 1st, 2nd, and 3rd Month.

Strengths and Weaknesses of the Study

One of the strengths of this study was that the method of calculation of blood loss was instructed to each participant at the first visit. Therefore, all the clients and investigators had a uniform definition of the qualitative variable (i.e. the volume of blood loss) in the study. Furthermore, the participants in each treatment arm were monitored for 3 cycles, which allowed for a more precise evaluation and comparison of the efficacy of the administered drugs.

As is the case in most longitudinal studies, some participants decided to not continue with the treatment during the course of the study, though in most cases $(38 \%)$, it was due to the fact that their condition had improved. This resulted in a decrease in our sample size.
Moreover, blinding was not possible with the patients and care providers, since tranexamic acid and mefenamic acid were supplied as tablets in the original blister pack.

Differences in Results and Conclusions

In a systematic review by Godfery et al, evidence suggests that intranasal desmopressin, tranexamic acid, or NSAIDs may be effective in treatment of bleeding irregularities; however, these treatments were only studied in a small number of patients and their safety has not been welldocumented. According to Godfery et al, "Level I to II1, fair to poor" evidence suggests that tranexamic acid and NSAIDs may prevent menorrhagia in Cu-IUD users, although "Level I, good" evidence suggests that NSAID 


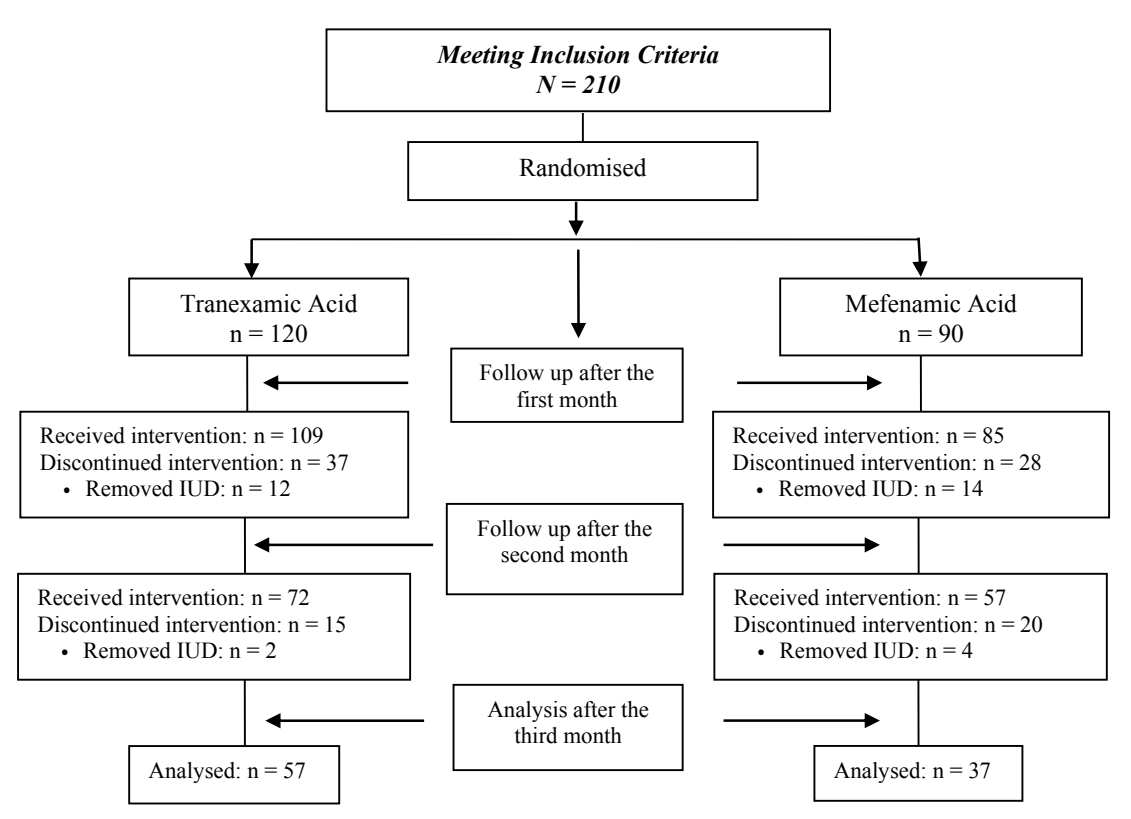

Figure 2. Design of the Study.

use may not influence continuation of the $\mathrm{Cu}$-IUD. The number of women who participated in these case studies were small and either the dosage of the drugs was high (tranexamic acid $1.5 \mathrm{~g}$ three times daily) or the drugs were administered for a long duration, such as for 7-10 days of the cycle during 6-7 cycles (2).

In a review study by Wellington and Wagstaff, tranexamic acid resulted in a greater reduction in bleeding (a 56\% decrease) compared to diclofenac sodium (a $24 \%$ decrease) and placebo (a 5\% decrease). However, neither tranexamic acid nor diclofenac sodium had any significant effects on the duration of menses. The dosage of tranexamic acid was $1.5 \mathrm{~g}$ three times daily for 5 days (9). In Coulter et al study, efficacy of NSAIDs and tranexamic acid were compared; volume of bleeding decreased by $29 \%$ and $47 \%$, respectively. The dosage of the drugs in this study was $500 \mathrm{mg}$ for mefenamic acid and 1-24 g for tranexamic acid (10). In Bonnar and Sheppard study, 3 drugs were compared: mefenamic acid, tranexamic acid, and ethamsylate. The rate of bleeding reduction was $20 \%$ and $54 \%$ for the first 2 drugs, respectively, but the third one had no significant effects. The dosage of the drugs in this study was $500 \mathrm{mg}$ for mefenamic acid and $1 \mathrm{~g}$ for tranexamic acid, administered four times daily for 5 days during 3 cycles (11). However, in our study, the dosage was $500 \mathrm{mg}$ three times daily for 3-5 days. In Ylikorkala and Viinikka study, tranexamic acid reduced the mean blood loss by $54 \%$ and diclofenac sodium resulted in a decrease of $20 \%$. The dosage of tranexamic acid was $1.5 \mathrm{~g}$ three times daily for 5 days during 2 cycles (7).

In Kaviani et al study, tranexamic acid was more effective than mefenamic acid for reduction of bleeding days as well as the volume of bleeding. Moreover, tranexamic acid had a quicker effect compared to mefenamic acid. The sample size of this case study was small (total $=58$ ) and the dosage of the drugs was smaller in comparison with our study:
$250 \mathrm{mg}$ three times daily for 3 days during 2 months (12). In Yavarikia et al study, the effect of mefenamic acid and vitagnus in reducing IUD-induced bleeding were compared. The effect of the 2 drugs was approximately the same after 4 months and in the mefenamic acid group, bleeding was reduced by $52 \%$. The dosage and duration of mefenamic acid use was $250 \mathrm{mg}$ three times daily for 8 days during 4 months (13).

In Najam et al study, the effects of a combination of tranexamic acid and mefenamic acid were compared with the effects of tranexamic acid alone. The combination drug reduced the bleeding by $59.3 \%$ and tranexamic acid alone reduced the bleeding by $50 \%$. The dosage of drugs in this study was $500 \mathrm{~g}$ tranexamic acid plus $250 \mathrm{mg}$ mefenamic acid for the combination group, and $500 \mathrm{mg}$ for the tranexamic group, administered 3 times daily for 5 days during 3 cycles. Improvement in $\mathrm{Hb}$ was observed after 6 months (14).

In our study, both drugs had the same effect on reducing the days of bleeding as well as the volume of bleeding. The difference between the results of our study compared to the other studies may be due to the difference in the dosage of the administered drugs and the duration of the treatment.

Relevance of the findings: Implications for Clinicians and Policymakers

IUD is a prevalent method of contraception. Accordingly, in order to improve its satisfaction level, we recommend that public health clinics administer these two drugs to their clients. Moreover, we suggest that the causes of discontinuation of IUD in clients be evaluated before and after the intervention.

Unanswered Questions and Future Research

The study aimed to compare the efficacy of tranexamic 
acid and mefenamic acid on reducing the duration of menstruation and volume of blood loss, as well as to evaluate their effect on the sequence of bleeding in TCu380A IUD users. During the course of the study, there were a number of participants who withdrew from the trial and discontinued their use of IUD. To gain a better understanding of the effect of the two administered drugs, further studies are therefore needed to evaluate the reasoning behind discontinuation of IUD.

\section{Conclusion}

Our results suggest that both drugs, tranexamic acid as an anti-fibrinolytic agent, and mefenamic acid as an NSAID, at dosage of $500 \mathrm{mg}$ three times daily for 3-5 days during 3 months have the same significant effects on Copper T-380A IUD-induced menorrhagia. Their effects are on both the volume of blood loss and the duration of menses. The peak effects of both drugs are at the end of the second month and the effect of tranexamic acid is more progressive. Comparison with other studies indicated that the dosage and the duration of treatment are important factors that influence the rate at which the drugs exert their effects.

\section{Ethical Issues}

The trial was conducted in accordance with principles of Infertility and Reproductive Health Research Centre (IRHRC) Ethics Committee of Shahid Beheshti University of Medical Sciences. Written informed consent was obtained from all subjects. Our trial has been registered with the Iranian Registry of Clinical Trials. The registration number is: IRCT2015012612494N3.

\section{Conflict of Interests}

The authors declare no conflict of interest in this study.

\section{Financial Support}

This study was approved and supported financially by the IRHRC affiliated to Shahid Beheshti University of Medical Science in Tehran, Iran.

\section{Acknowledgments}

The authors wish to thank Dr. Pourhoseingholi, who assisted in statistical analyses. They also gratefully acknowledge the staff of the IRHRC, the 6 public health clinics, as well as all the women who participated in this clinical trial.

\section{References}

1. Berek JS, Novak E. Berek and Novak's Gynecology. 15th ed. Philadelphia: Wolters Kluwer, Lippincott Williams and Wilkins; 2012:211-70. doi:10.1007/s13224-014-0538-z.
2. Godfrey EM, Folger SG, Jeng G, Jamieson DJ, Curtis KM. Treatment of bleeding irregularities in women with copper-containing IUDs: a systematic review. Contraception. 2013;87(5):549-566. doi:10.1016/j. contraception.2012.09.006.

3. Hoffman BL, Schorge JO, Schaffer JI, Halvorson LM, Bradshaw KD, Cunningham FG. Williams Gynecology. 2nd ed. USA: McGraw-Hill Education; 2012:219.

4. Roy SN, Bhattacharya S. Benefits and risks of pharmacological agents used for the treatment of menorrhagia. Drug Saf. 2004;27(2):75-90. doi:10.2165/00002018-20042702000001.

5. Grimes DA, Hubacher D, Lopez LM, Schulz KF. Nonsteroidal anti-inflammatory drugs for heavy bleeding or pain associated with intrauterine-device use. Cochrane Database Syst Rev. 2006;(4):CD006034. doi: 10.1002/14651858.CD006034.

6. World Health Organization. Selected Practice Recommendations for Contraceptive Use. 2nd ed. Geneva: WHO; 2004.

7. Ylikorkala O, Viinikka L. Comparison between antifibrinolytic and antiprostaglandin treatment in the reduction of increased menstrual blood loss in women with intrauterine contraceptive devices. Br J Obstet Gynaecol. 1983;90(1):78-83. doi:10.1111/j.1471-0528.1983.tb06751.x.

8. Food and Drug Administration. FDA approves lysteda to treat heavy menstrual bleeding. United States: Food and Drug Administration; 2009 Nov. https://wayback. archive-it.org/7993/20170113011729/http://www.fda. gov/NewsEvents/Newsroom/PressAnnouncements/2009/ ucm190551.htm. Accessed May 12, 2014

9. Wellington K, Wagstaff AJ. Tranexamic acid: A review of its use in the management of menorrhagia. Drugs. 2003;63(13):1417-1433. doi: 10.2165/00003495-20036313000008.

10. Coulter A, Kelland J, Peto V, Reese MC. Treating menorrhagia in primary care: an overview of drug trials and a survey of prescribing practice. Int J Technol Assess Health Care. 1995;11(3):456-71. doi: 10.1017/S0266462300008679.

11. Bonnar J, Sheppard BL. Treatment of menorrhagia during menstruation: randomised controlled trial of ethamsylate, mefenamic acid, and tranexamic acid. BMJ. 1996;313(7057):579-82. doi:10.1136/bmj.313.7057.579.

12. Kaviani M, Roozbeh N, Azima S, Amoi S. Comparing the effects of tranexamic acid and mefenamic acid in IUDinduced menorrhagia: randomized controlled trial. Int J Community Based Nurs Midwifery. 2013;1(4):216-223.

13. Yavarikia $P$, Shahnazi M, Hadavand Mirzaie S, Javadzadeh Y, Lutfi R. Comparing the effect of mefenamic acid and vitex agnus on intrauterine device induced bleeding. J Caring Sci. 2013;2(3):245-254. doi: 10.5681/jcs.2013.030.

14. Najam R, Agarwal D, Tyagi R, Singh S. Comparison of traneximic acid with a combination of traneximic acid and mefenamic acid in reducing menstrual blood loss in ovulatory dysfunctional uterine bleeding (DUB). J Clin Diagn Res. 2010;4(5):3020-3025.

Copyright ( 2017 The Author (s); This is an open-access article distributed under the terms of the Creative Commons Attribution License (http://creativecommons.org/licenses/by/4.0), which permits unrestricted use, distribution, and reproduction in any medium, provided the original work is properly cited. 